\title{
Speech and Communication Disorders: A Case Study as a Teaching Example of Lifelong Training for All
}

\author{
Vasiliki Ioannidi, Elli Samara \\ Hellenic Open University, Patras, Greece \\ Email: ioannidi.vasiliki@ac.eap.gr,samara.elli@ac.eap.gr
}

How to cite this paper: Ioannidi, V. and Samara, E. (2019) Speech and Communication Disorders: A Case Study as a Teaching Example of Lifelong Training for All. Open Access Library Journal, 6: e5162. https://doi.org/10.4236/oalib.1105162

Received: January 2, 2019

Accepted: January 13, 2019

Published: January 16, 2019

Copyright $\odot 2019$ by author(s) and Open Access Library Inc.

This work is licensed under the Creative Commons Attribution International License (CC BY 4.0).

http://creativecommons.org/licenses/by/4.0/ (c) (i) Open Access

\begin{abstract}
Speech and communication disorders are a category of special educational needs and can affect the evolution of the individual. The aim of this report is to present a case study as a teaching example. While studying this case, real or hypothetical examples, which reflect more general situations, are presented in order to analyze and investigate them thoroughly. The purpose of this is to provide alternative solutions to the emerging problems. The presentation of written case studies can become a really important part of the educational procedure. Case studies form the core of the recognition process and signify the end of a successful training. Moreover, case studies are an important element for lifelong training of both educators and therapists. A hypothetical case is presented in this report together with the symptomatology it shows. Furthermore, the diagnosis procedure and the way the problems of the specific student have been dealt with are presented. Finally, some basic conclusions are reached based on the information that has already been presented.
\end{abstract}

\section{Subject Areas}

Education

\section{Keywords}

Speech, Communication Disorders, Special Education, Lifelong

Training for All

\section{Introduction}

Communication as an interactive exchange of information, ideas, feelings, needs and desires is a vital element of human experience. It refers to coding, transmis- 
sion and decoding of messages. Language is a standard code that group members use in order to communicate with each other and speech is the oral production of the language [1].

More specifically, language is a system of sounds and meanings. It constitutes a code that enables communication between the members of a group on the condition that these people are aware of this system and they know how to comply with its rules regarding a phonological, vocal, morphological, syntactic and semantic level. Respectively, disorders or disfunctions in linguistic development can concern one or more of these levels, and can appear either as problems of information acquisition and perception of speech or as weakness of expression. The linguistic abilities of a child can affect social interaction, e.g. in relationships with peers, family members, and later in the professional and wider social environment. Therefore, communication disorders and linguistic disorders in particular, are strongly associated with the academic and social development of the individual. Consequently, timely and valid detection, recognition, and intervention play a vital role regarding not only the improvement of linguistic abilities but also of other related developmental areas. The developmental deficits that affect speech perceptions increase the risk of linguistic and literacy problems, which may lead to reduced academic and professional achievements [2] [3] [4].

Hence, the symptomatology of these problems needs timely detection and immediate dealing since it can affect the emotional balance of a child, his/her learning and cognitive performance, interpersonal relationships and social adaptation. Last but not least, good cooperation among specialists, family and educators is of vital importance in solving problems of speech.

\section{Study Case}

Here, we will analyze the case study, e.g. presentation, symptoms, diagnosis and treatment.

\subsection{Presentation}

The specific student attends the first grade of Primary School, has normal mental background and typical psychokinetic development. Also, he is willing to communicate; he has good concentration, satisfactory kinetic coordination in both subtle and rough movements without any difficulty in chewing or swallowing food.

However, this student uses limited vocabulary, substitutes sounds and makes grammar and syntax errors while using the language. As a result, these linguistic problems impede both school attendance at a learning level and his social interaction with his peers.

Furthermore, being teased by some of his peers may have a negative emotional impact on his social isolation and lack of self-confidence inside the classroom. Therefore, any positive attitude he has towards his self-image diminishes, and 
the student needs pediatric-pedagogical examination and rehabilitation.

\subsection{Symptoms}

The student indicates the following symptoms:

- He has disturbed phonology in terms of expression and comprehension. This means that simplifications, omissions or toner replacements are observed.

- At the same time, there is a weakness regarding understanding and differentiation of the notes, e.g. between " $k$ " and " $t$ ". This creates a problem in the pronunciation of the sounds.

- More often than not, he has difficulty pronouncing " $r$ " and that is why he may substitute the specific sound.

- Moreover, the student finds it hard to understand that two words might suggest the same meaning e.g. book-volume.

- In addition, the student struggles to use a wide range of vocabulary. He cannot use more sophisticated words and he usually describes what he wants to name, e.g. instead of saying "pencil", he might mention: "the thing we write with".

\subsection{Diagnosis}

The diagnosis is not a superficial classification but rather an analysis of the various linguistic educational conditions highlighting the existing difficulties [5].

The pupil's assessment included data, like:

- Individual, family and school student's background,

- Logopedic assessment,

- Check of the student's hearing ability,

- Neurological check and examination,

- Learning and cognitive examination.

Useful data was recorded based on WHOQOL-100 [6], like:

- Individual background e.g. developmental stage, emotional state of the student, health problems, learning difficulties, attitude problems, issues of linguistic development, various needs etc.

- Family/social background e.g. family relationships and social circumstances, family tree, physical and psychological situation of the members of the family, standard of living, etc.

- School background e.g. classroom comments, school performance, personal adjustment and behavior both in the classroom and in the school community, interests and talents of the student, cooperation with the family, etc.

- Support planning-Education e.g. teaching strategies that have been used, etc.

- Interdisciplinary cooperation e.g. any involvement of other health and education practitioners, etc.

To sum up, the student based on the diagnostic tests that have been used [7] [8] [9] shows phonological and language expression disorder and faces moderate communication difficulty, something that may cause difficulty in academic fields 
and may even contribute to making mistakes in reading and writing [10]. There was cooperation with the family and the parents accepted the suggestion for educational support.

\subsection{Treatment}

In the context of planning the preparation of teaching, the teacher should make sure that he takes organizational measures so that teaching has the anticipated success [11].

The treatment of the linguistic disorders of the specific student was based on a therapeutic combination of speech therapy, pedagogic support and rehabilitation, as well as psychological support of the student and parent counseling.

Additionally, the teaching activities were as follows:

- In the language field, e.g. language skills exercises by conquering a desired mental level of thinking and language, orthodontic exercises etc.

- In the kinesthetic field, e.g. acoustic and visual movements of distinguishing sounds, exercises for correct articulation, etc.

- In the psychosocial field, e.g. miming exercises, correct facial expressions, pedagogic and psychological assistance towards enhancing acceptable behaviors, etc.

- In the mental field, e.g. vocabulary expansion, exercises for finding the correct word within a sentence, exercises for production of speech in phonological, grammar and syntax level.

Overall, the activities were aimed at a specific pedagogic treatment together with the psychological support of the child, at informing parents and educators and at developing good educational practices [12]. Aiming in this way, emphasis was given on the following:

- communication should be pleasant,

- the teacher should motivate and encourage the child,

- should respond to the child's needs immediately and directly,

- should listen carefully,

- ought to speak clearly and repeat where necessary,

- should be descriptive,

- has to provide educational opportunities and useful information to the student,

- should use grammar and syntax standards and correct the student in a creative learning environment.

Furthermore, the parents were sensitized in the following direction: The student's problems of speech and communication should no longer create more social and attitude disorders, by establishing these emotional and behavioral disorders permanently.

\section{Conclusions}

According to contemporary findings [13], what is important is the timely and 
valid recognition of the problems, the immediate beginning of the appropriate treatment and the spherical nature of the intervention in disorders. At this point, the philosophy of inclusion can be added [14] [15], where children with special educational needs or/and disabilities should have priority in the general classroom, in which suitable adjustments should be made according to 1) the environment, 2) teaching, 3) material, 4) school curriculum, 5) assessment, 6) interaction within the classroom and the school community, 7) the support of the rest of the staff, etc.

In these adjustments, the therapeutic framework should be added which is advisable to include gaming activities, e.g. phonological exercises with cards and the development of the child's creativity through games. In this way, the reduced self-esteem of the child enhances and improves not only as far as his self-image is concerned, but also regarding the relations with his peers.

Moreover, interdisciplinary cooperation among health professionals and educators is of vital importance, since communication is a function which involves many interdependent factors [16] and speech is one of the most complex cortical, cognitive and mental functions. To put it in a nutshell, for the effective educational and therapeutic treatment and intervention of speech disorders, it is of vital importance to use knowledge from various specialties/scientists.

\section{Conflicts of Interest}

The authors declare no conflicts of interest regarding the publication of this paper.

\section{References}

[1] Heward, W.L. (2009) Exceptional Children. An Introduction to Special Education. Pearson Education, NJ.

[2] Voulgaris, D. (2000) Problems in the Vocal-Phonological Level of Pre-School Children's Language (In Greek: Provlimata sto fonitiko-fonologiko epipedo tiw glossas pedion prosholikis ilikias). In: Kipriotakis, A., Ed., Special Education Conference Proceedings, Pedagogical Department of Elementary Education, School of Education Sciences, University of Crete, Rethimno, 518-535.

[3] Hoff, E. (2014) Language and Development. Cengage Learning, Wadsworth.

[4] Tallal, P. (2004) Improving Language and Literacy Is a Matter of Time. Nature Reviews Neuroscience, 5, 721-728. https://doi.org/10.1038/nrn1499

[5] Antor, G. and Bleidick, U. (Hrsg.) (2001) Handlexikon der Behindertenpädagogik. Schlüsselbegriffe aus Theorie und Praxis. Stuttgart.

[6] World Health Organization (2003) Manual of Quality of Life with a Questionnaire Axis WHOQOL-100. Psychiatric Clinic of the University of Athens. BHTA Editions, Athens. (In Greek: Eghiridio piotitas zois me axona to erotimatologio WHOQOL-100).

[7] Vogindroukas, I., Grigoriadou, E. and Kampouroglou, M. (2009) The Language Perception and Expression Test (In Greek: $\mathrm{H}$ dokimasia glossikis antilipsis kai ekfrasis). Glafki Editions, Athens.

[8] Vogindroukas, I., Protopapas, A. and Sideridis, G. (2009) Expressing Vocabulary Test (In Greek: Dokimasia ekfrastikou lexilogiou). Glafki Editions, Athens. 
[9] Vogindroukas, I., Protopapas, A. and Stavrakaki, S. (2009) Action Images. Information and Grammar Proficiency Test (In Greek: Ikones drasis. Dokimasia pliroforiakis ke ekfrastikis eparkias). Glafki Editions, Athens.

[10] Bishop, D.V.M. and Snowling, M.J. (2004) Developmental Dyslexia and Specific Language Impairment: Same or Different? Psychological Bulletin, 130, 858-886. https://doi.org/10.1037/0033-2909.130.6.858

[11] Kapsalis, A. (2002) Modern Teaching (In Greek: Sighroni didaktiki). Editions of the University of Macedonia, Thessaloniki.

[12] Bontsiou, Th. (2014) Guide to the Role of Speech Therapist in the School Context of General Education (In Greek: Odigos gia ton therapefti logou sto sholiko plesi genikis ekpedefsis). Institute of Educational Policy, Athens.

[13] Fletcher, J.M., Reid Lyon, G., Fuchs, L.S. and Barnes, M.A. (2019) Learning Disabilities. From Identification to Intervention. The Guilford Press, New York, London.

[14] Campbell, C. (2002) Developing Inclusive Schooling: Perspectives, Policies and Practices. Institute of Education, University of London, London.

[15] Norwich, B. (2008) What Future for Special Schools and Inclusion? Conceptual and Professional Perspectives. British Journal of Special Education, 35, 136-143. https://doi.org/10.1111/j.1467-8578.2008.00387.x

[16] Bontsiou, Th. (2014) Guide for Interdisciplinary Cooperation of the Speech Therapist and Good Practices for All Levels of Education (In Greek: Odigos diepistimonikis sinergasias tou therapefti logou ke kales praktikes gia oles tis vathmides ekpedefsis). Institute of Educational Policy, Athens. 